\title{
CONSTRUINDO $O$ DIÁLOGO ENTRE COMPETÊNCIA, RECURSOS E DESEMPENHO ORGANIZACIONAL
}

\section{RESUMO}

Este artigo objetiva estudar como os recursos impactam o desempenho organizacional. Partindo da noção de competência como processo de coordenação e mobilização de recursos, utilizou-se o referencial do balanced scorecard (BSC) para mensurar a influência dessa coordenação sobre os indicadores de desempenho nas múltiplas perspectivas do BSC. A revisão da literatura sobre esse tema mostrou que se privilegia o uso de indicadores financeiros ou de processos internos, e que menos estudos avaliam indicadores de aprendizagem, impactos sobre os clientes, ou analisam mais de uma perspectiva simultaneamente. Um estudo de caso em profundidade em empresa de saneamento utilizando dados e indicadores sugere que fatores ambientais relacionados à demanda são os maiores determinantes do desempenho. A satisfação dos funcionários sugere associação com todas as perspectivas do BSC.

\section{Bruno Henrique Rocha Fernandes}

Centro Universitário Positivo

\section{Maria Tereza Leme Fleury \\ FEA-USP}

\section{John Mills}

Institute for Manufacturing - University of Cambridge

\begin{abstract}
This paper deals with the question of how resources affect organizational performance. It assumes competence as a bundle of coordinated resources and employs the Balanced Scorecard (BSC) framework to measure and assess how this coordination influences performance indicators all over BSC perspectives. A review effort in this field showed that financial or internal process indicators are the most considered; performance indicators from learning and growth perspectives or studies evaluating simultaneously all performance perspectives are less common. A case study in a Brazilian water company, using firm's data and indicators, pointed external factors related to demand to be the strongest performance determinant; employee satisfaction presented association with all BSC perspectives.
\end{abstract}

PALAVRAS-CHAVE Competências organizacionais, desempenho organizacional, balanced scorecard, visão da empresa baseada em recursos, sistema de gestão de pessoas de alta performance.

KEYWORDS Organizational competences, organizational performance, performance measurement and Balanced Scorecard, resource based view of a firm, high performance working systems. 


\section{INTRODUÇÃO}

Nos últimos anos, o debate sobre competências organizacionais assumiu uma importância crescente, extrapolando os muros da academia, sobretudo com a obra de Prahalad e Hamel (1990) sobre competências essenciais. Um aspecto pouco enfatizado nessas discussões diz respeito às raízes teóricas do conceito de competência, imbricadas na visão da empresa baseada em recursos (RBV, do inglês resource based view), proposta por Penrose (1959). Nessa perspectiva, uma organização pode ser entendida como um conjunto de recursos empregados para gerar riquezas. O conceito de competência organizacional deriva dessa visão, e está relacionado ao conjunto de recursos coordenados que afetam o desempenho da organização.

Como mensurar o desempenho organizacional é outro tema debatido, sendo o modelo do balanced scorecard (BSC) o mais utilizado para organizar as diversas perspectivas do desempenho. Porém, analisando as pesquisas sobre recursos, verificamos que os mais estudados são práticas de $\mathrm{RH}$ e, geralmente, desempenho equivale a desempenho financeiro. Poucos estudos abordam simultaneamente indicadores em mais de uma perspectiva do BSC (por exemplo, indicadores de processos internos, clientes e financeiros), e mais de uma categoria de recursos (por exemplo, práticas de RH, satisfação e competências dos funcionários).

Observando tais lacunas, este trabalho procurou focar a seguinte questão, baseado em uma situação concreta: que recursos influenciam o desempenho organizacional, considerando diversas categorias de recursos, mas, em especial, recursos ligados à gestão de pessoas, e mensurando o desempenho por meio de indicadores que cobrem todas as perspectivas do BSC?

Uma pesquisa realizada numa empresa do setor de saneamento objetivou explorar empiricamente essa questão. $\mathrm{Na}$ ocasião, a empresa dispunha de uma estrutura com 93 unidades de negócios (UNs) e um sistema de avaliação da performance baseado no BSC. Essa empresa possuía unidades comparáveis, avaliadas pelos mesmos indicadores, estabelecendo interessante base para investigar a relação entre recursos e indicadores de performance.

O artigo está estruturado em quatro partes. A primeira faz uma revisão teórica dos conceitos propostos e recupera estudos empíricos relacionando os recursos à performance organizacional. A segunda discorre sobre os procedimentos metodológicos que orientaram a pesquisa. A terceira descreve o caso que serve de base para a análise. A quarta, a conclusão, reflete sobre os resultados alcançados no estudo.

\section{RECURSOS, COMPETÊNCIA E DESEMPENHO: ARTICULAÇÃO DOS CONCEITOS}

\section{Recursos e competências organizacionais}

Na perspectiva da RBV, uma organização pode ser entendida como um conjunto de recursos empregados de maneira produtiva para gerar riqueza. Boa parte dos esforços investigativos dos teóricos da RBV consiste em classificar tais recursos. Por exemplo, a própria Penrose (1959, p. 24) propôs duas classes de recursos: físicos e humanos. A primeira consiste em coisas tangíveis, como prédios, equipamentos, terra e recursos naturais, e matéria-prima. A segunda se refere às diversas classes de empregados de uma empresa, do "chão de fábrica" à administração. Wernerfelt (1984, p. 172) também sugeriu duas categorias, denominando-as ativos tangíveis e ativos intangíveis. Há inúmeras propostas de categorização (Barney, 1991 e 1996; Leonard, 1995). Este artigo assume a de Mills et al. (2002), como está no Quadro 1.

Para os teóricos da RBV, recursos são elementos potenciais, um estoque à disposição da organização, cuja simples existência não se traduz necessariamente em desempenho. É preciso que tais recursos sejam mobilizados, coordenados e "entregues" para se garantir a performance organizacional. Essa instância de mobilização e coordenação de recursos pode ser denominada competência organizacional. Mills et al. (2002) afirmam que uma competência resulta de um conjunto de recursos coordenados de modo a determinar um nível particular de performance numa atividade. Por exemplo, considerese a Figura 1, em que o triângulo ilustra a competência velocidade no lançamento de novos produtos em uma organização. Quando analisada de modo pormenorizado, conclui-se que tal competência resulta da coordenação de recursos como uma equipe tecnicamente preparada e motivada, um sistema de recompensa à inovação e uma boa integração entre Marketing e P\&D.

Usando termos distintos, outros autores compartilham a idéia da relação entre RBV e competências. ${ }^{1}$ Por exemplo, Hamel (1994, p. 11) conceitua "competências" como uma "integração de habilidades e tecnologias, em vez de uma habilidade ou tecnologia única e isolada". A literatura sugere fatores que conferem valor a uma competência. Prahalad e Hamel (1990) citam o benefício oferecido a clientes, a dificuldade de imitar e o acesso a diferentes mercados. Barney (1996) enumera valor, raridade ou singularidade, impossibilidade de imitar e substituir, e versatilidade ou capacidade de transferir o recurso. Mills et al. (2002) sintetizam isso em três medidas: valor, sustentabilidade e versatilidade. 
Um último elemento importante para caracterizar competências organizacionais é o fato de agregarem valor em fatores-chaves de sucesso para a organização. Os fatores-chaves de sucesso (key success factors ou KSF) sinalizam que, para cada setor, há atributos específicos que os players devem atender para permanecer no negócio. A competência se relaciona a um desempenho superior num KSF: um desempenho superior em aspecto irrelevante num setor - por exemplo, ser forte em design quando o cliente busca apenas preço - não caracteriza competência significativa.

Integrando tais conceitos, este artigo sugere que "competência organizacional" seja definida como um conjunto de recursos coordenados que geram valor à organização, são difíceis de imitar, podem ser transferidos a outras áreas, produtos ou serviços da organização, e impactam o desempenho organizacional em um fator-chave a seu sucesso.

\section{Competências organizacionais e desempenho}

Da discussão precedente, observa-se que o conceito de competência organizacional leva ao de desempenho. Este se refere aos resultados que uma organização atinge num período. Há, porém, diversas áreas de resultados em uma organização, tantas quantas forem os seus stakeholders,

\section{Quadro 1 - Categoria de recursos organizacionais}

\section{CATEGORIA DE RECURSOS}

Tangiveis

Conhecimentos, habilidades

e experiências

Procedimentos e sistemas

Valores e cultura

\section{Networks}

(redes de relacionamento)

Importante para a mudança

\section{DESCRIÇÃO}

Construções, plantas, equipamentos, licenças exclusivas, posição geográfica, patentes, empregados.

Conjunto freqüentemente tácito cujos possuidores muitas vezes não sabem que têm.

Conjunto de documentos tangíveis: sistemas de recrutamento e seleção, avaliação de desempenho e recompensa, processo de compras, etc. Embora tangiveis, exigem recursos intangiveis para funcionar eficientemente.

Recurso intangível desenvolvido ao longo do tempo, quase sempre dependente das atitudes dos fundadores e eventos passados. Incluem memória de incidentes críticos, valores, crenças.

Grupos de interesse dentro da empresa, networks de pessoas da empresa com fornecedores, clientes, governo, consultores. Inclui marca e reputação.

Reconhecer quando recursos valiosos se tornam ultrapassados e necessitam mudar ou mesmo ser destruídos.

Fonte: Adaptado de Mills et al. (2002, p. 20-21)

Figura 1 - Competência: velocidade no lançamento de novos produtos e recursos constitutivos

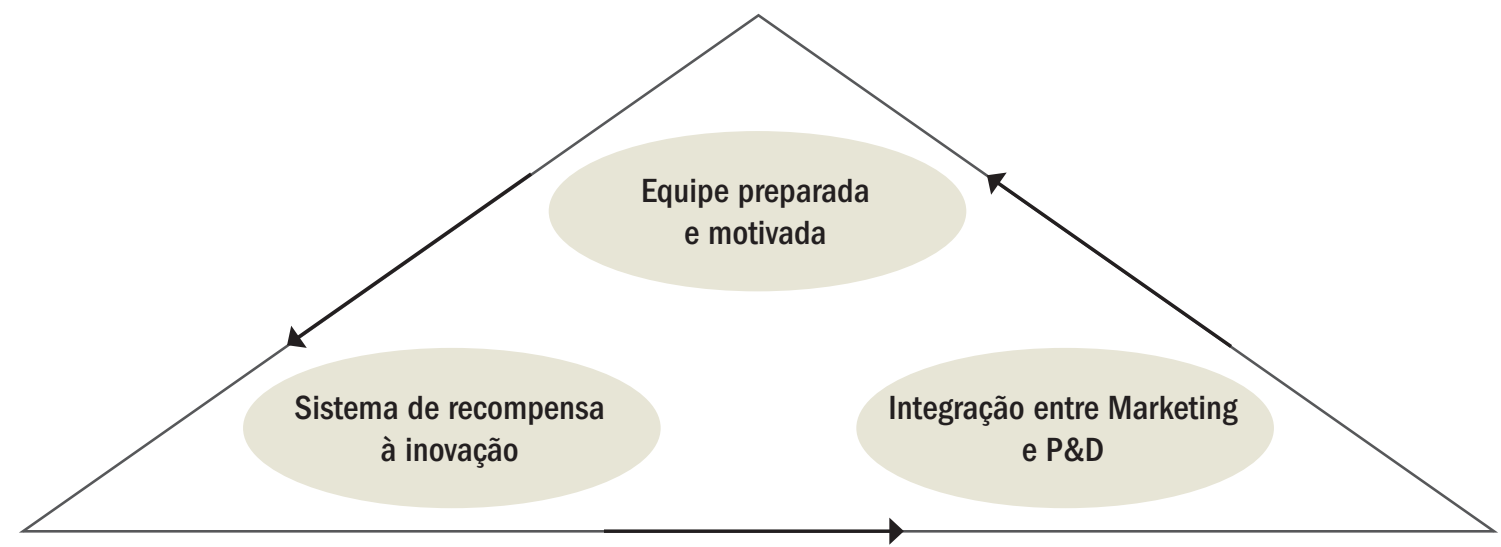

Fonte: Mills et al. (2002, p. 14). 
com diferentes interesses e expectativas de resultados muitas vezes conflitantes (Cameron, 1986).

A questão remete ao modo como a organização mede seus resultados. Tradicionalmente, as empresas mensuravam predominantemente resultados financeiros, privilegiando o stakeholder acionista. Tais modelos de mensuração eram insatisfatórios, não apenas por não contemplarem outras partes interessadas, mas por serem historicamente orientados (Henri, 2004). Além disso, Kennerley e Neely (2003) concluem que fornecem pouca informação para o desempenho futuro, encorajam uma visão de curto prazo, são orientados mais internamente do que externamente, com pouco foco em clientes e concorrentes, carecem de visão estratégica e freqüentemente inibem a inovação.

A fim de contornar vieses nos sistemas tradicionais, novos modelos de mensuração de performance vêm surgindo, procurando enfocar fatores além de financeiros. Destes, o mais famoso é o balanced scorecard (BSC), de Kaplan e Norton (1992), ainda que não seja o único, nem isento a críticas (Henri, 2004). Propõem os autores que as empresas monitorem seu desempenho segundo quatro perspectivas: financeira, clientes, processos internos e aprendizagem. A perspectiva financeira considera o valor criado pela empresa. As medidas típicas incluem rentabilidade, crescimento e valor para o acionista. A perspectiva dos clientes aborda os mercados que a organização procura atender, com medidas como satisfação, retenção e aquisição de clientes, e participação de mercado. A perspectiva de processos internos se refere à maneira como a empresa estrutura suas atividades para entregar produtos e serviços. As medidas são: tempo de ciclo operacional, indicadores de qualidade, de flexibilidade, entre outros. Por fim, a perspectiva de aprendizagem e crescimento, "identifica a infra-estrutura que a empresa deve construir para gerar crescimento e melhoria a longo prazo" (Kaplan e Norton, 1997, p. 29). Inicialmente, Kaplan e Norton incluem na perspectiva: capacitação dos empregados, sistemas de informações de capacitações, motivação, empoderamento e alinhamento.

Os autores sugerem uma relação causal entre as seguintes perspectivas: melhor capacitação de empregados e infra-estrutura (aprendizado e crescimento) melhorará a eficiência em processos (processos internos), deixará os clientes mais satisfeitos e com intenção de comprarem novamente (clientes), e, conseqüentemente, a margem de lucro aumentará (finanças) (Kaplan e Norton, 1992).

A perspectiva de aprendizado do BSC encontra paralelo no que este trabalho denomina "competência organizacional". Afinal, a perspectiva de aprendizagem é constituí- da de fatores que poderiam ser traduzidos por recursos, segundo a terminologia da RBV. Componentes como a satisfação dos empregados, o nível de habilidades e competências, o compartilhamento de informações, políticas e procedimentos, e a liderança - que Kaplan e Norton (1992; 1996) colocam na perspectiva de aprendizado - coincidem com os diferentes recursos que, articulados, constituem uma competência organizacional.

A Figura 2 ilustra a relação entre competência e desempenho, usando a noção de mapas causais, própria da metodologia do BSC, substituindo a perspectiva de aprendizado pelo símbolo que Mills et al. (2002) propõem para competência. Ainda, reserva-se o termo desempenho para sinalizar as perspectivas de processos, clientes e financeiras.

Sintetizando, a competência organizacional consiste na mobilização de recursos, e sua aplicação aparecerá no desempenho, manifestado em indicadores escolhidos para as perspectivas de processos, clientes e financeiras do BSC. ${ }^{2}$ Dentre os recursos constitutivos da competência, este artigo se ocupa principalmente com aqueles ligados ao capital humano e à gestão de pessoas. Afirmam Becker e Gerhart que:

[...] de acordo com a RBV, as empresas podem desenvolver vantagem competitiva sustentável somente criando valor numa maneira que é escassa e difícil para os concorrentes imitarem. Embora as fontes tradicionais de vantagem competitiva como recursos naturais, tecnologia, economias de escala, e assim por diante, gerem valor, a RBV sugere que tais recursos são cada vez mais fáceis de imitar, especialmente quando comparados com estruturas sociais complexas como o sistema de trabalho. Se isto é assim, então as estratégias de recursos humanos podem ser especialmente importantes como fonte de vantagem competitiva sustentável. (BECKER e GERHART, 1996, p. 781-782).

A fim de melhor entender a relação proposta entre recursos ligados ao fator humano e ao desempenho, este estudo efetuou uma revisão de trabalhos empíricos no campo. Essa revisão procurou levantar pesquisas de acordo com os seguintes critérios: a) com nível de análise organizacional, não individual; b) que examinassem variáveis ligadas a recursos humanos, mesmo que incluíssem também outros recursos; ; e c) que mensurassem algum indicador de desempenho influenciado pelos recursos.

Por variáveis relacionadas ao fator humano (item b) entendem-se práticas de RH, índices de satisfação, treinamento e competência. Vários desses indicadores são utilizados 
para avaliar a efetividade da área de RH (Becker et al., 2001). Ainda que cultura organizacional e valores também possam ser considerados recursos (Barney, 1991; Leonard, 1995), estes não foram incluídos por constituírem vasto campo de literatura que extrapola o foco deste estudo. De forma geral, foram identificadas três categorias de pesquisas, quais sejam: estudos na área de Recursos Humanos, no campo de Marketing e na área de Estratégia.

\section{Estudos na área de Recursos Humanos}

O primeiro grupo inclui pesquisas na área de Recursos Humanos que visam testar em que medida o uso de sistemas de trabalho de alta performance (high performance work systems - HPWS) está associado ao melhor desempenho empresarial. HPWS é a expressão usada para definir - vagamente - inovações no ambiente de trabalho, como equipes semi-autônomas, sistemas de planejamento participativos, desenhos inovadores de plantas, remuneração elevada e uso intensivo de práticas de RH (Farias e Varma, 1998). Enquadram-se nesse grupo os trabalhos de Arthur (1994), abordando o efeito de práticas de RH sobre turnover e performance operacional, Macy e Farias (apud Farias e Varma, 1998), investigando indicadores financeiros, desempenho comportamental e qualidade de vida no trabalho em empresas com HPWS, Husselid (1995, com estudo reeditado em 1997 e 1999), avaliando o efeito da adoção conjunta de uma série de práticas, em vez de práticas isoladas. Outros trabalhos contemplaram contextos culturais diferentes do americano, como Bae e Lawler (2000), focando empresas coreanas, e Guthrie (2001), examinando empresas da Nova Zelândia.

Em geral, tais estudos demonstram relações relativamente fracas ou inexistentes entre práticas de RH e desempenho (Becker e Gerhart, 1996; Farias e Varma, 1998;

Figura 2 - Relação entre competências e desempenho organizacional

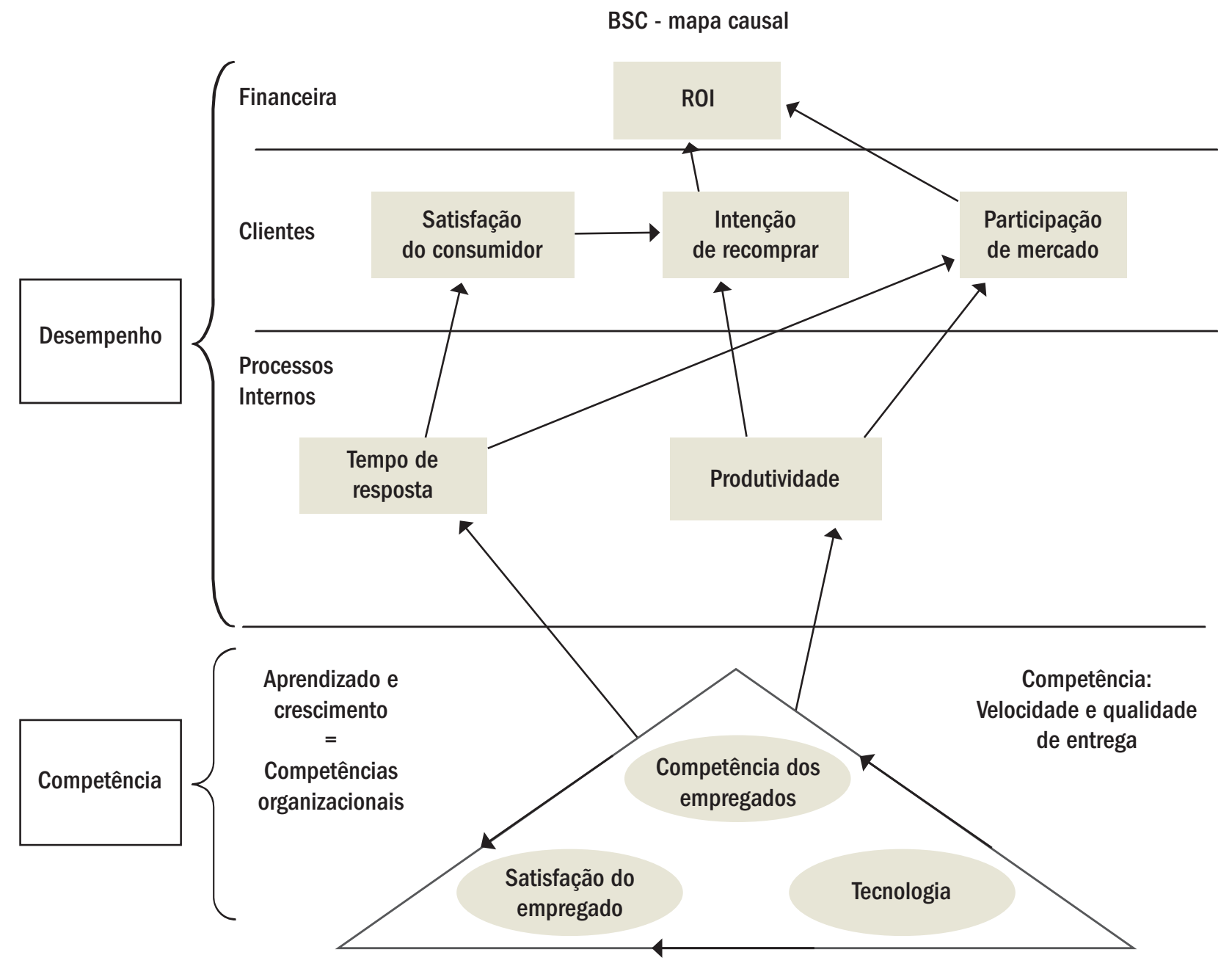


Mueller, 1996). Mueller (1996, p. 771) sustenta que a simples existência de práticas não acarreta melhores resultados, e tais práticas serão efetivas se "acompanharem processos subjacentes de formação de habilidades, que podem ser facilitados ou acelerados, mas não substituídos, pelas atividades da ARH (...) [e] se os recursos humanos trabalharem em sintonia com outros recursos, isto se houver interdependência entre os recursos".

Outros autores focaram variáveis além das práticas de RH. Varma et al. (1999), examinando a satisfação dos empregados como driver do desempenho, observaram que a maior satisfação dos empregados estava relacionada ao aperfeiçoamento da performance operacional e financeira. Fulmer et al. (2003), pesquisando empresas de capital aberto entre as 100 melhores para se trabalhar nos Estados Unidos - no ano de 1998 -, constataram que relações de trabalho positivas estavam relacionadas à superioridade em indicadores como retorno sobre ativos e valor de mercado sobre valor contábil, se comparadas a empresas do mercado em geral, e superioridade nos retornos para acionistas a longo prazo, quando comparadas a uma amostra de empresas semelhantes. Hitt et al. (2001), examinando escritórios de advocacia, abordaram a relação do capital humano com a performance. Entre outros, notaram correlação entre maior capital humano e desempenho financeiro superior.

Os trabalhos de Batt (2002) e Gales et al. (2002) estudaram a relação entre as habilidades dos funcionários e o desempenho. Batt (2002) observou que os call centers que enfatizam o desenvolvimento das habilidades dos funcionários possuem menor rotatividade. Gales et al. (2002), estudando transformações recentes na manufatura, notaram que maiores níveis de automação e produtividade estão associados a maiores exigências de habilidades das pessoas.

\section{Estudos na área de Marketing}

Outros autores, principalmente na área de Marketing, concentraram esforços para entender em que medida a satisfação dos empregados se transformava em satisfação e lealdade do consumidor - o chamado "espelho da satisfação": clientes satisfeitos refletem funcionários felizes - e em rentabilidade. Essa idéia, proposta por Heskett et al. (1997), enfatizando o setor de serviços, foi batizada de cadeia lucro-serviços. Porém, eles basearam suas constatações em diversos estudos sobre os elos separados da cadeia, em vez de em um único estudo que avaliasse todas as ligações nas mesmas organizações. Isso motivou uma abrangente pesquisa de Barber et al. (1999), cobrindo 65 mil funcionários, 25 mil clientes de 100 empresas de varejo britânicas, que concluiu existir uma relação entre a satisfação do funcionário e a do cliente. Porém, o desempenho financeiro era mais previsível pela intenção de comprar novamente do que pela satisfação do cliente.

Outros estudos versam sobre essa relação. Hoffman e Ingram (1992) constataram a influência positiva da satisfação no trabalho com o desempenho orientado para o cliente em serviços. Pugh (2001) estudou como as emoções do funcionário influenciam as dos clientes e, por sua vez, impactam na avaliação percebida do serviço. Susskind et al. (2003) verificaram que o apoio de colegas e supervisores afeta a determinação de padrões do serviço e como esse influencia a orientação para os clientes e sua satisfação.

\section{Estudos da área de Estratégia e mensuração da performance}

Este grupo é constituído de experiências de implantação de sistemas de mensuração da performance em empresas, investigando a relação entre desenvolvimento da perspectiva de aprendizagem e indicadores operacionais, de clientes e financeiros. Podem ser citados os trabalhos de Rucci et al. (1998), descrevendo a cadeia lucro-serviços na Sears; Becker et al. (2001) na GTE; Schay et al. (2002) no governo federal americano; Kaplan e Norton (2001, 2004) na Mobil, Store 24, Northwestern Mutual e Volvo Finance; e Neely e Najjar (2003) na British Airways. De forma geral, tais estudos consistem em reflexões sobre projetos de implantação de sistemas de avaliação do desempenho. Primeiro, desenvolvem e implantam indicadores para diversas perspectivas de performance, conforme a estratégia da empresa. A seguir, coletam dados desses indicadores e analisam, mediante técnicas estatísticas, a associação entre os indicadores nas diferentes perspectivas.

O Quadro 2 apresenta alguns trabalhos empíricos que relacionam recursos ligados à gestão de pessoas e performance organizacional. O referencial do BSC foi utilizado para classificar os estudos. Na primeira coluna, os recursos ligados a pessoas, incluídos na perspectiva de aprendizado e crescimento, correspondem a variáveis independentes; as demais colunas correspondem a variáveis dependentes. Nos estudos, foram identificados os seguintes recursos: práticas de RH, turnover, motivação dos empregados (satisfação e conscientização para estratégia, relações de trabalho favoráveis), capital humano e habilidades. As pesquisas são classificadas segundo os recursos (variáveis independentes) e indicadores de desempenho (variáveis dependentes) examinados.

A análise desses estudos, corroborada com o levantamento de outros autores (Becker e Gerhart, 1996; Becker et al., 2001), permite inferir algumas conclusões. Uma é que ainda poucos estudos cobrem todas as perspectivas 
do desempenho organizacional simultaneamente. Os poucos estudos que abarcaram todas as perspectivas, como o de Bae e Lawler (2000), basearam-se em indicadores de percepção, não verificando se HPWS estavam associados a um aumento real na satisfação do cliente, mas se estavam correlacionados à percepção, pelo respondente, de que o cliente estaria mais contente.

Uma segunda observação é que muitos estudos se concentram nas práticas de RH como drivers de performance. Menor número de estudos aborda outros recursos, como satisfação, capital intelectual ou competências. Talvez isso ocorra porque os direcionadores de performance são específicos à empresa ou, pelo menos, ao setor. Por exemplo, o driver satisfação do funcionário pode ter impacto maior na Sears, loja de departamento em que os vendedores têm grande interação com os clientes, do que em supermercados, voltados ao auto-serviço. Ademais, a relação entre estabilidade de pessoal e performance pode ser bem distinta para pesquisadores num laboratório farmacêutico e atendentes numa cadeia de fast food.

Ora, se cada empresa possui direcionadores diferentes para alavancar o desempenho, como escolher um determinado e avaliar seu impacto sobre negócios distintos? Isso pode explicar por que estudos com outros drivers tendem a se concentrar em um setor - como escritórios de advocacia para Hitt et al. (2001), ou call centers para Batt (2002) - ou mesmo em organizações específicas, como os estudos relacionados à implantação do BSC.

\section{Quadro 2 - Estudos empíricos na relação entre recursos organizacionais e desempenho}

\begin{tabular}{|c|c|c|c|c|}
\hline $\begin{array}{c}\text { VARIÁVEIS } \\
\text { INDEPENDENTES }\end{array}$ & \multicolumn{4}{|c|}{$\begin{array}{c}\text { VARIÁVEIS } \\
\text { DEPENDENTES }\end{array}$} \\
\hline $\begin{array}{l}\text { Aprendizagem/ } \\
\text { Recursos }\end{array}$ & $\begin{array}{l}\text { Aprendizagem/ } \\
\text { Recursos } \\
\text { (turnover, com- } \\
\text { portamento, qua- } \\
\text { lidade de vida, } \\
\text { habilidades dos } \\
\text { funcionários) }\end{array}$ & $\begin{array}{l}\text { Processos internos (pro- } \\
\text { dutividade, qualidade, ino- } \\
\text { vação, velocidade, recei- } \\
\text { ta/empregado, tempo de } \\
\text { resposta, lead time, ciclo } \\
\text { de projeto) }\end{array}$ & $\begin{array}{l}\text { Clientes (satisfação do } \\
\text { cliente, intenção de re- } \\
\text { comprar, emoções, par- } \\
\text { ticipação de mercado, } \\
\text { força da marca) }\end{array}$ & $\begin{array}{l}\text { Financeira (lucro, valor de } \\
\text { mercado/ valor contábil, } \\
\text { crescimento de vendas, efi- } \\
\text { ciência, custos, ativos, ROA, } \\
\text { ROI) }\end{array}$ \\
\hline Práticas de RH & $\begin{array}{l}\text { Arthur (1994) } \\
\text { Macy et al. (1995) } \\
\text { Husselid (1995) } \\
\text { Delaney et al. } \\
\text { (1996) } \\
\text { Guthrie (2001) } \\
\text { Batt (2002) }\end{array}$ & $\begin{array}{l}\text { Arthur (1994) } \\
\text { Husselid (1995, 1997, } \\
\text { 1999) } \\
\text { Delaney et al. (1996) } \\
\text { Varma et al. (1999) } \\
\text { Bae et al. (2000) } \\
\text { Guthrie (2001) } \\
\text { Hitt et al. (2001) }\end{array}$ & $\begin{array}{l}\text { Delaney et al. (1996) } \\
\text { Bae et al. (2000) }\end{array}$ & $\begin{array}{l}\text { Macy et al. (1995) } \\
\text { Husselid (1995, 1997, } \\
\text { 1999) } \\
\text { Delaney et al. (1996) } \\
\text { Varma et al. (1999) } \\
\text { Bae et al. (2000) } \\
\text { Batt (2002) }\end{array}$ \\
\hline Turnover & & $\begin{array}{l}\text { Becker et al. (2001) } \\
\text { Schay et al. (2002) }\end{array}$ & Schay et al. (2002) & Batt (2002) \\
\hline $\begin{array}{l}\text { Motivação dos empre- } \\
\text { gados (satisfação e } \\
\text { conscientização para } \\
\text { estratégia, orientação } \\
\text { para o cliente e mer- } \\
\text { cado, relações de tra- } \\
\text { balho favoráveis, emo- } \\
\text { ções, apoio de colegas } \\
\text { e chefia) }\end{array}$ & & $\begin{array}{l}\text { Varma et al. (1999) } \\
\text { Schay et al. (2002) } \\
\text { Kaplan e Norton (2001) }\end{array}$ & $\begin{array}{l}\text { Hoffman et al. (1992) } \\
\text { Heskett et al. (1997) } \\
\text { Rucci et al. (1998) } \\
\text { Barber et al. (1999) } \\
\text { Pugh (2001) } \\
\text { Schay et al.(2002) } \\
\text { Kaplan e Norton (2001) } \\
\text { Neely e Najjar (2003) } \\
\text { Susskind et al. (2003) }\end{array}$ & $\begin{array}{l}\text { Heskett et al. (1997) } \\
\text { Rucci et al. (1998) } \\
\text { Barber et al. (1999) } \\
\text { Varma et al. (1999) } \\
\text { Kaplan e Norton (2001) } \\
\text { Neely e Najjar (2003) } \\
\text { Fulmar et al.(2003) }\end{array}$ \\
\hline $\begin{array}{l}\text { Capital humano } \\
\text { Habilidades }\end{array}$ & $\begin{array}{l}\text { Gales et al. } \\
(2002)\end{array}$ & $\begin{array}{l}\text { Hitt et al. (2001) } \\
\text { Schay et al. (2002) } \\
\text { Kaplan e Norton (2004) }\end{array}$ & $\begin{array}{l}\text { Schay et al. (2002) } \\
\text { Kaplan e Norton (2004) }\end{array}$ & $\begin{array}{l}\text { Batt (2002) } \\
\text { Kaplan e Norton (2004) }\end{array}$ \\
\hline
\end{tabular}


Por outro lado, todas as organizações possuem práticas de RH mais ou menos sofisticadas. Daí que vários estudos tenham escolhido tais práticas para testar até que ponto sua sofisticação estaria relacionada à performance. Porém, a constatação de relações relativamente fracas aponta para a necessidade de mergulhar em outros drivers ou recursos para entender o que determina um desempenho superior.

Outra dificuldade relacionada à escolha de direcionadores está na operacionalização das medidas. Considere-se o conceito de competências/habilidades como direcionador. Nos estudos consultados, mesmo quando se pensou em incluí-lo, ou não foi possível mensurá-lo (como Kaplan e Norton, 2001, na Mobil), ou transfigurou-se o conceito para operacionalizá-lo (como Batt, 2002, que operacionaliza competência como "anos de exercício na função").

Tais constatações apontam para a necessidade de aprofundar estudos sobre a relação entre competências/recursos organizacionais e performance, tema deste artigo. Em particular, tais estudos deveriam privilegiar os seguintes aspectos: (a) avaliar a performance em suas múltiplas perspectivas simultaneamente; e (b) incluir outros recursos ou direcionadores da performance, como competências individuais, ativos tangíveis, satisfação, etc., além das práticas de RH.

O presente estudo investiga essas questões, orientado pela seguinte pergunta de pesquisa: que recursos influenciam o desempenho organizacional, considerando diversas categorias de recursos - em especial aqueles ligados a pessoas e gestão de pessoas - e abordando o desempenho de forma abrangente, medido por indicadores de todas as perspectivas do BSC?

\section{PROCEDIMENTOS METODOLÓGICOS}

Para a investigação se optou por realizar um estudo de caso exploratório. A idéia foi conduzir a pesquisa num setor ou empresa que tivesse unidades comparáveis, em número suficiente para tratamento estatístico, e em que se pudessem medir recursos e graus de performance com o uso dos mesmos indicadores. Outra decisão foi que, em vez de chegar com um recorte predefinido, com variáveis prontas para serem coletadas, procurou-se entender que recursos e indicadores os membros das organizações em estudo julgavam importantes para a obtenção de êxito no desempenho, cobrindo todas as perspectivas do BSC. A partir desses contornos, a pesquisa foi desenhada para constatar se aqueles recursos estavam de fato associados ao melhor desempenho nos indicadores definidos.
A empresa escolhida foi a Sanepar (Companhia Paranaense de Saneamento). Criada em 1963 para fornecer tratamento de água e esgoto no estado do Paraná, a empresa em 2002 faturou cerca de R \$ 1 bilhão, empregando 4 mil funcionários diretos. Os dados coletados se referem ao ano de 2002.

Desde 1997 sua estrutura organizacional consiste em dois níveis: uma holding no nível corporativo, e unidades de negócio (UNs) no nível operacional. O nível corporativo é responsável por decisões centralizadas como processo de investimento, planejamento de longo prazo e P\&D. As UNs são de dois tipos: unidades de serviço (US), cujo papel é oferecer serviços no mercado interno para outras UNs, e unidades de receita (UR), que lidam com clientes externos. As USs incluem áreas administrativas como Recursos Humanos, Contabilidade, Informática e Jurídica, e áreas de prestação de serviços técnicos de engenharia. Obtêm sua receita por meio de um sistema de transferência de preços internos. $\mathrm{Na}$ ocasião da pesquisa, a empresa possuía 93 UNs, sendo 38 URs.

O sistema de gestão é inspirado no BSC, embora a empresa não siga o modelo rigorosamente. No início do ciclo de planejamento anual, a UN detalha suas metas de acordo com o planejamento estratégico central. Tais metas são desdobradas em indicadores de performance para cada perspectiva do BSC. Durante o processo, gestores das UNs negociam com unidades fornecedoras, clientes e pares para definirem números factíveis. Após chegarem a consenso, apresentam os valores para o nível corporativo. Se aprovados, transformam-se em metas da UN para o próximo exercício. Parte da remuneração variável está condicionada ao alcance dessas metas. O sistema de gestão é monitorado pelo software SGS, que armazena os indicadores das UNs. Em 2002 esse software foi premiado pela Microsoft como a melhor solução em business intelligence na América Latina (Sanare, 2002, p. 3).

$\mathrm{Na}$ ocasião, a empresa adotava um sistema de gestão de pessoas baseado em competências. Entre outras informações, o sistema registrava uma avaliação do nível de competência de cada funcionário da empresa, segundo nove competências, quais sejam: relacionamento interpessoal, aprimoramento de processos, orientação ao cliente, responsabilidade e autonomia, gestão do conhecimento, visão do negócio, gestão integrada de projetos, orientação a resultados, e multifuncionalidade. Para cada competência, o funcionário era avaliado por sua chefia numa escala de 1 (não atende), 2 (em desenvolvimento), 3 (atende) e 4 (supera), de acordo com seu nível de proficiência na competência. O modelo de competências era monitorado 
pelo software Sistema de Competências e Relações com Empregados (SCRE).

Possuir um sistema de avaliação de performance, um sistema de gestão de pessoas baseado em competências e uma estrutura organizacional com unidades comparáveis fez da empresa campo privilegiado para se investigar a relação entre recursos e performance. Para o estudo, escolheu-se um tipo particular de UN: as URs.

Para operacionalizar a pesquisa, foram estabelecidas as seguintes etapas: (a) definir, com os integrantes da empresa, uma competência organizacional para as URs e seus recursos componentes, utilizando a metodologia arquitetura de competências e recursos (Mills et al., 2002); (b) definir resultados e indicadores importantes que as unidades deveriam buscar dentro de cada perspectiva do BSC; (c) estabelecer, por meio de mapas causais, as ligações entre recursos e indicadores de performance; (d) coletar dados junto aos sistemas de informação da empresa, quando já monitorados, ou desenvolver e aplicar instrumento de coleta específico no caso de dados não disponíveis; (e) aplicar técnicas de análise fatorial visando identificar fatores (ou variáveis reduzidas) que explicassem parte significativa da variância em cada perspectiva do BSC; e (f) conduzir análises de regressão para verificar associações entre variáveis reduzidas, fossem elas recursos ou indicadores de performance.

Para a etapa (a), usou-se a metodologia arquitetura de competências e recursos, de Mills et al. (2002), da seguinte forma: identificou-se um fator-chave de sucesso no setor e se avaliou o valor, a sustentabilidade e a versatilidade do fator, a fim de caracterizá-lo ou não como competência, sempre com o uso de questionários estruturados. A partir disso, o KSF de maior relevância foi escolhido como competência organizacional para análise. Tal competência foi decomposta em recursos constitutivos, que foram medidos. Assumiu-se que quanto maior a quantidade e qualidade dos recursos, maior o nível da competência organizacional e, conseqüentemente, melhor o desempenho.

$\mathrm{Na}$ etapa (b), avaliaram-se quais os resultados mais importantes que as unidades deveriam buscar, e quais indicadores expressavam tais resultados. Os indicadores deveriam ser escolhidos em todas as perspectivas do BSC.

A etapa (c) consistiu em construir mapas causais, ligando recursos a indicadores selecionados. Relações da causalidade foram representadas mediante setas saindo da variável independente para a dependente, que poderia transformar-se em independente em relações consecutivas. Destaca-se, porém, que, embora o grupo tenha expressado relações causais, a pesquisa investigou apenas associações. As etapas (a), (b) e (c) foram desenvolvidas mediante entrevistas e workshops com um grupo de sete gestores da empresa.

Na etapa (d), examinaram-se as diversas bases de dados da empresa visando obter as informações necessárias à pesquisa. As informações foram buscadas no nível das UNs e separadas em variáveis de recursos e variáveis de desempenho. As variáveis de recursos foram divididas por um denominador comum - o número de ligações de água e esgoto da unidade - para assegurar comparabilidade. Por exemplo, tem pouco sentido comparar o número de funcionários de uma unidade que atende uma região com 100 mil pessoas com outra que atende 10 mil. Porém, o quociente entre o número de funcionários e o de ligações de água e esgoto das localidades é comparável. Para variáveis de desempenho, examinou-se o quociente entre metas e resultados alcançados, ou seja, o quanto as unidades realizaram frente a suas metas.

Uma informação relevante não estava disponibilizada por tais sistemas: o grau de automação das unidades. Para tal informação foi concebido um questionário, aplicado nas unidades de serviços de manutenção eletromecânicas, USEMs. As USEMs foram escolhidas porque são responsáveis pela manutenção dos equipamentos de toda a empresa e, por isso, têm visão abrangente do nível de automação de cada unidade.

As etapas (e) e (f) foram rodadas mediante o uso do software estatístico SPSS e da planilha Excel, recurso "análise de dados". Foram observadas cautelas referentes às condições de uso das técnicas, no que respeita à normalidade da amostra e indicadores para a aceitação dos resultados. Na etapa (e), foi necessária a redução no número de variáveis pelos seguintes motivos: algumas variáveis originais continham praticamente as mesmas informações, o número excessivo de variáveis poderia mascarar fenômenos relevantes, e a limitação da amostra requeria poucas variáveis. Assim, as variáveis foram reduzidas a um número menor de fatores, que foram rotacionados para se obter maior facilidade de interpretação. Utilizou-se o método de rotação ortogonal Varimax com normalização de Kaiser porque os resultados se utilizariam em análises estatísticas posteriores, que exigiram multicolinearidade mínima nos dados. Para aceitar as variáveis reduzidas nas análises seguintes observou-se a medida de adequação da amostra de Kaiser-Meyer-Olkin (KMO, ideal para valores superiores a 0,7 ), que avalia a validade do modelo como um todo. Por fim, à exceção da perspectiva de aprendizado, para as demais se tomaram as variáveis reduzidas com maior poder explicativo da variância, devido a limitações do tamanho da amostra. Na etapa (f) foram inseridas duas variáveis que, se desconsideradas, poderiam enviesar os 
resultados. As análises de regressão limitaram a oito o número de variáveis a serem incluídas no modelo, para se manter a proporção de cinco casos por variável, conforme (Hair et al., 1998, p. 142).

O nível de análise da pesquisa é organizacional, e as unidades de análise foram as 38 URs. A investigação é horizontal e comparativa, pois comparou recursos e desempenho das unidades num dado momento do tempo (dezembro de 2002). A pesquisa é qualitativa, ao modelar recursos constitutivos, competências e mapas causais; e quantitativa, ao tratar estatisticamente dados coletados.

\section{APRESENTAÇÃO DOS RESULTADOS}

Em relação à arquitetura de competência e recursos, nas entrevistas e workshops com gestores, foi destacada como principal competência das unidades o foco em resultados. Utilizando a metodologia proposta por Mills et al. (2002) (veja Quadro 1 e Figura 1), levantaram-se os recursos que seriam necessários à efetivação da competência. Na Figura 3 estão expostos os resultados.

Acerca da escolha de indicadores de desempenho, o Quadro 3 mostra os indicadores considerados mais impor- tantes para as URs, na opinião dos gestores da empresa.

O grupo também concebeu o mapa cognitivo que liga recursos a perspectivas da performance. A Figura 4 ilustra parte do mapa resultante. Nela, a seta que sai da perspectiva de aprendizado e aponta para a produtividade sinaliza que um aumento na competência organizacional foco em resultados trará incremento à produtividade; esta, por sua vez, implicará redução nas despesas de pessoal e aumento na Ebitda. À diferença do que propõe parte da literatura, neste caso o grupo considerou que o nível de satisfação do cliente não interfere nos resultados financeiros, pois o consumidor não consumirá mais ou menos água segundo sua satisfação com o serviço.

Em relação à coleta de dados, para localizar onde poderiam ser obtidas informações referentes às variáveis de recursos e desempenho, a atenção se voltou para os sistemas de gestão da empresa. O Quadro 3 mostra as variáveis investigadas, suas definições operacionais e as fontes de onde foram extraídas.

\section{Análise fatorial}

O modelo proposto pelo grupo revelou-se demasiadamente complexo para ser submetido a testes estatísticos. Assim, o passo seguinte foi a análise fatorial, a fim de se obter, para

Figura 3 - Arquitetura de recursos: competência "foco em resultados" para URs

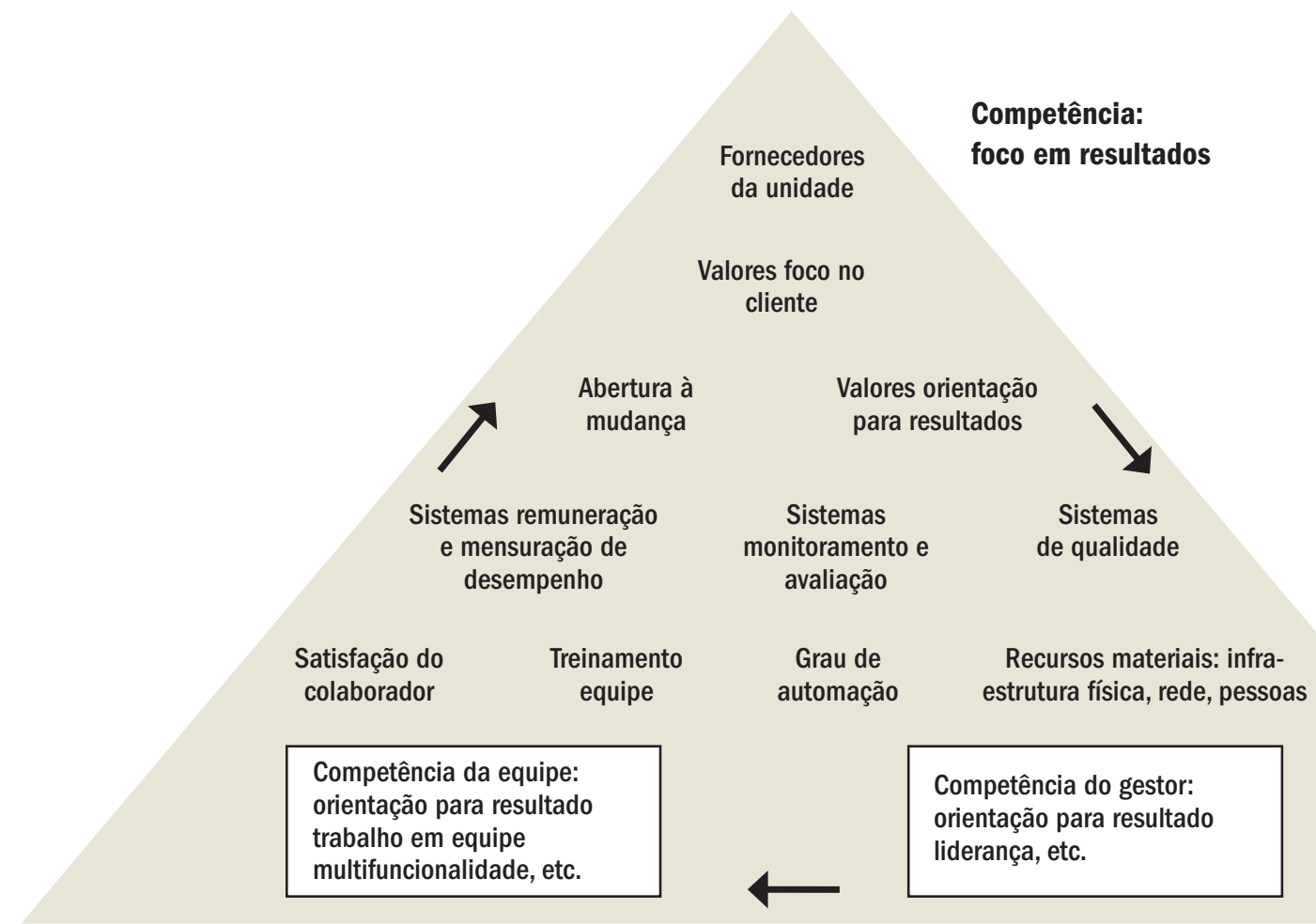


cada perspectiva do BSC, o fator que explicaria a maior parte da variância. A Tabela 1 apresenta as variáveis aceitas, segundo critérios explicados na seção sobre metodologia. É importante destacar que as variáveis usadas em cada análise fatorial são medidas por escalas similares.

Na perspectiva financeira, a redução revelou dois componentes: o primeiro relacionado à receita operacional e o segundo, as despesas de diversas categorias (exploração e pessoal), traduzindo a variação conjunta desses fatores. O componente mostrou que as URs que atingem ou superam os resultados de arrecadação e receita também o fazem nas despesas. O segundo componente expressou a variação conjunta de resultados líquidos e margem operacional. Os fatores foram batizados respectivamente receitas e despesas e indicadores financeiros líquidos para os componentes 1 e 2, respectivamente. Destes, o fator escolhido para análises subseqüentes foi o primeiro, por explicar a maior parte da variância.

Na perspectiva de clientes, apenas duas variáveis foram consideradas para a análise fatorial: satisfação do cliente e número de reclamações. Outras variáveis que haviam sido representadas no mapa causal, como acréscimo no número de ligações (de água e esgoto) e atendimento (também de água e esgoto), para efeitos de análise, foram incluídas na perspectiva de processos internos. Embora o procedimento tenha agrupado as variáveis com carregamento expressivo no componente $(0,824)$ e na direção esperada, com sentidos invertidos (quanto maior o número de reclamações, menor a satisfação), optou-se por não adotar a redução, em virtude dos baixos valores para KMO e comunalidade. Para efeito de análises estatísticas posteriores, utilizou-se apenas a variável satisfação do cliente.

$\mathrm{Na}$ perspectiva de processos internos, em função do número de variáveis, a análise fatorial foi aplicada a dois conjuntos de variáveis. O primeiro conjunto envolveu indicadores relativos a volume de operação e o segundo abarcou outras perspectivas. Para o primeiro grupo, a análise separou os dados em duas categorias: variáveis referentes ao alcance das metas quanto ao produto "água", e variáveis referentes ao alcance das metas para o produto "esgoto". Desses componentes, escolheu-se apenas o primeiro, por representar $60 \%$ da variância.

Para o segundo grupo, a redução apontou três componentes: um relativo a reparos e consertos; outro vinculado às perdas do sistema; e ainda um referente a interrupções no abastecimento de água. Embora a associação das variáveis em cada fator tenha sentido, os fatores não foram considerados para efeito de análises posteriores em virtude de o valor do KMO estar abaixo do especificado para a pesquisa $(\mathrm{KMO}=0,613<0,70)$.

Por fim, na perspectiva de aprendizado e crescimento, os dados foram divididos em desempenho dos fornecedores, competências humanas e demais recursos. O desempenho dos fornecedores não foi incluído nos procedimentos de

Figura 4 - Representação de parte do mapa cognitivo causal elaborado pelo grupo de gestores

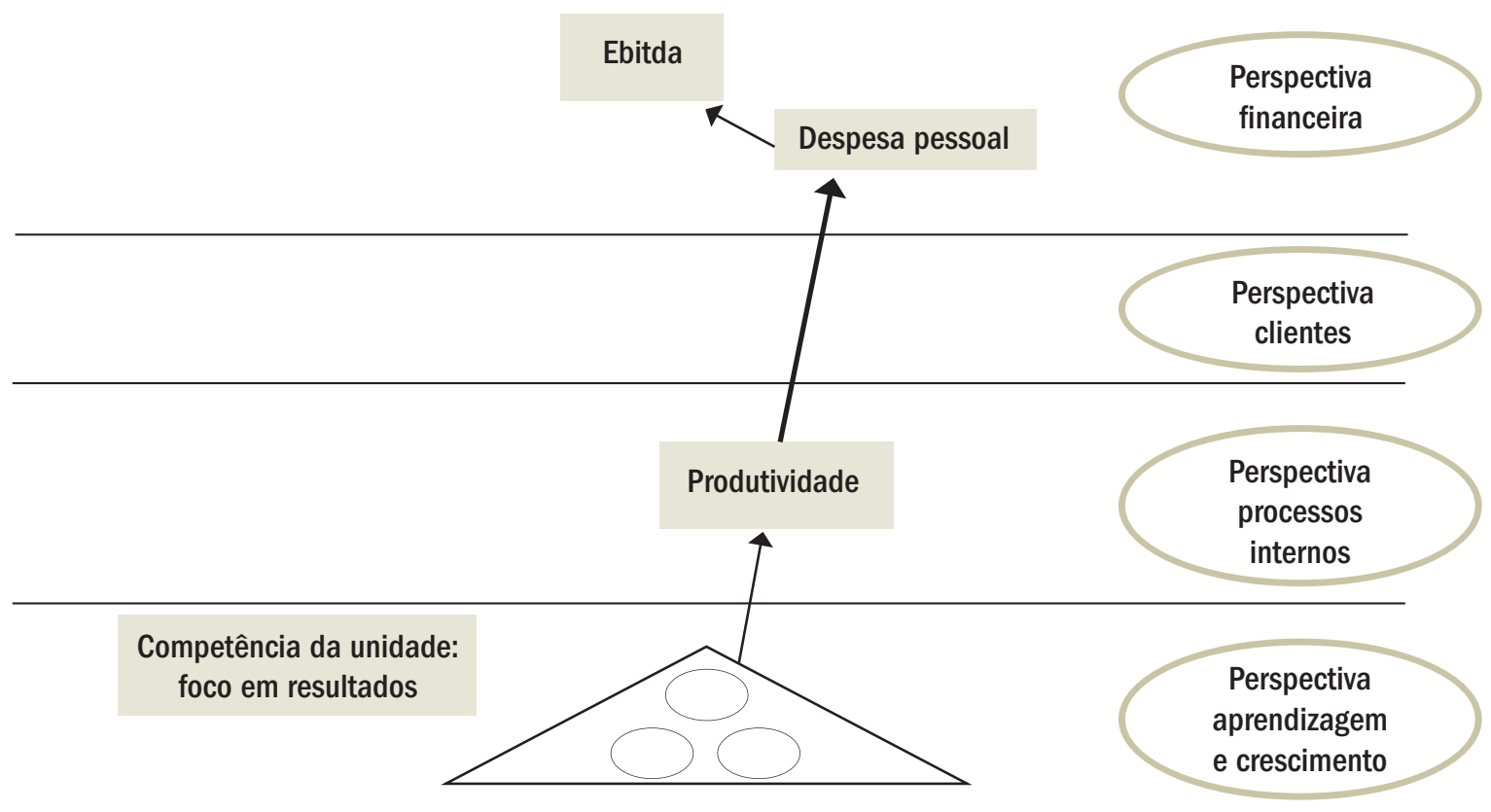


Quadro 3 - Variáveis de pesquisa: explicação, escala utilizada e fonte dos dados

\begin{tabular}{|c|c|c|c|c|}
\hline PERSPECTIVA & INDICADORES & EXPLICAÇÃO & ESCALA/MEDIDA & FONTE \\
\hline \multirow{4}{*}{ Financeira } & Ebitda & $\begin{array}{l}\text { Resultado da unidade antes dos juros, impostos, depreciações } \\
\text { e amortizações }\end{array}$ & \multirow{8}{*}{ Meta/realizado } & \multirow{8}{*}{ SGS } \\
\hline & Despesas da UR & $\begin{array}{l}\text { Percentual da receita operacional com despesas de pessoal e } \\
\text { despesas operacionais }\end{array}$ & & \\
\hline & $\begin{array}{l}\text { Margem } \\
\text { operacional }\end{array}$ & Percentual da receita operacional com despesas & & \\
\hline & $\begin{array}{l}\text { Receita operacio- } \\
\text { nal ajustada }\end{array}$ & $\begin{array}{l}\text { Somatória da receita tarifária mais receita de serviços para } \\
\text { clientes externos }\end{array}$ & & \\
\hline \multirow{6}{*}{ Clientes } & $\begin{array}{l}\text { Aumento liga- } \\
\text { ções água }\end{array}$ & Número de ligações de água que a unidade aumentou & & \\
\hline & $\begin{array}{l}\text { Aumento liga- } \\
\text { ções esgoto }\end{array}$ & Número de ligações de esgoto que a unidade aumentou & & \\
\hline & $\begin{array}{l}\text { Nivel atendimen- } \\
\text { to água }\end{array}$ & Nível de cobertura com serviços de água & & \\
\hline & $\begin{array}{l}\text { Nível atendimen- } \\
\text { to esgoto }\end{array}$ & Nível de cobertura com serviços de esgoto & & \\
\hline & $\begin{array}{l}\text { Satisfação dos } \\
\text { clientes }\end{array}$ & $\begin{array}{l}\text { Pesquisa de satisfação composta de atributos para avaliar } \\
\text { produtos e serviços quanto a operação, manutenção, atendi- } \\
\text { mento e projetos e obras }\end{array}$ & \multirow{2}{*}{$\begin{array}{l}\text { Escala de } \\
0,0 \text { a } 100,0\end{array}$} & \multirow{2}{*}{ SGS } \\
\hline & $\begin{array}{l}\text { Total de } \\
\text { reclamações }\end{array}$ & $\begin{array}{l}\text { Soma das reclamações classificadas em: faturamento; ser- } \\
\text { viços prestados; operação do sistema (falta de água, água } \\
\text { suja, etc.) }\end{array}$ & & \\
\hline \multirow{8}{*}{$\begin{array}{l}\text { Processos } \\
\text { internos }\end{array}$} & $\begin{array}{l}\text { № ligações de } \\
\text { água }\end{array}$ & Quantidade de ligações de água da unidade & \multirow{8}{*}{ Meta/realizado } & \multirow{8}{*}{ SGS } \\
\hline & $\begin{array}{l}\text { № ligações de } \\
\text { esgoto }\end{array}$ & Quantidade de ligações de esgoto da unidade & & \\
\hline & Produtividade & $\begin{array}{l}\text { Quantidade de ligações de água e esgoto para cada empre- } \\
\text { gado da unidade }\end{array}$ & & \\
\hline & $\begin{array}{l}\text { Perdas no } \\
\text { faturamento }\end{array}$ & $\begin{array}{l}\text { Relação entre o volume produzido e o faturado. Compõe per- } \\
\text { das físicas e não-físicas com desvios de medição e volumes } \\
\text { utilizados e não cobrados }\end{array}$ & & \\
\hline & $\begin{array}{l}\text { Índice de perdas } \\
\text { distribuição }\end{array}$ & Volume produzido disponibilizado e não utilizado. & & \\
\hline & $\begin{array}{l}\text { Refluxos de } \\
\text { esgoto }\end{array}$ & $\begin{array}{l}\text { Número de refluxos ocorridos para cada } 1.000 \text { ligações de } \\
\text { esgoto }\end{array}$ & & \\
\hline & $\begin{array}{l}\text { Reposição de } \\
\text { pavimentos }\end{array}$ & $\begin{array}{l}\text { Percentual de serviços de reposição de pavimentos com prazo } \\
\text { de execução igual a } 10 \text { dias em relação ao total de serviços } \\
\text { de reposição de pavimentos }\end{array}$ & & \\
\hline & $\begin{array}{l}\text { Interrupção no } \\
\text { Abastecimento }\end{array}$ & Horas de interrupção no abastecimento de água no ano & & \\
\hline
\end{tabular}


continuação Quadro 3

\begin{tabular}{|c|c|c|c|c|}
\hline \multirow{10}{*}{$\begin{array}{l}\text { Apredizagem } \\
\text { (recursos) }\end{array}$} & $\begin{array}{l}\text { Treinamento } \\
\text { funcionário }\end{array}$ & $\begin{array}{l}\text { Número de funcionários com mais de } 20 \text { horas de treinamen- } \\
\text { to/ano em relação ao número de ligações de água da UR }\end{array}$ & $\begin{array}{l}\text { № de funcionários } \\
\text { treinados }>20 \mathrm{~h} / \\
\text { ligações UR }\end{array}$ & SGS \\
\hline & $\begin{array}{l}\text { Satisfação } \\
\text { funcionários }\end{array}$ & Pesquisa de clima organizacional & $\begin{array}{l}\text { Escala de } \\
0,0 \text { a } 100,0\end{array}$ & SGS \\
\hline & $\begin{array}{l}\text { Grau de } \\
\text { automação }\end{array}$ & $\begin{array}{l}\text { Grau de automação dos sistemas de distribuição da UR. Leva } \\
\text { em conta percentual de unidades operativas automatizadas e } \\
\text { existência de centro de controle operacional informatizado }\end{array}$ & $\begin{array}{l}\text { Escala likert } \\
\text { de } 1 \text { a } 5\end{array}$ & $\begin{array}{l}\text { Questio- } \\
\text { nário }\end{array}$ \\
\hline & $\begin{array}{l}\text { Recursos } \\
\text { materiais }\end{array}$ & $\begin{array}{l}\text { Infra-estrutura física administrativa e rede em relação ao nú- } \\
\text { mero de ligações de água da UR }\end{array}$ & $\begin{array}{l}\text { Valor patrimonial } \\
\text { unidade/ ligações } \\
\text { UR }\end{array}$ & SGS \\
\hline & $\begin{array}{l}\text { Número } \\
\text { funcionários }\end{array}$ & $\begin{array}{l}\text { Quantidade de funcionários da UR em relação ao número de } \\
\text { ligações de água da UR }\end{array}$ & $\begin{array}{l}\text { № de funcioná- } \\
\text { rios/ ligações } \\
\text { UR }\end{array}$ & SGS \\
\hline & Horas extras & $\begin{array}{l}\text { Quantidade de horas extras usadas na UR em relação ao nú- } \\
\text { mero de ligações de água da UR }\end{array}$ & $\begin{array}{l}\text { Valor patrimonial } \\
\text { da unidade/ liga- } \\
\text { ções UR }\end{array}$ & SGS \\
\hline & Fornecedores & $\begin{array}{l}\text { Qualidade do trabalho dos fornecedores da UR (UNs produção } \\
\text { e UNs manutenção) }\end{array}$ & $\begin{array}{l}\text { Índice qualida- } \\
\text { de água (produ- } \\
\text { ção) e retrabalho } \\
\text { (manutenção) }\end{array}$ & SGS \\
\hline & $\begin{array}{l}\text { Competên- } \\
\text { cia profissional } \\
\text { gestor }\end{array}$ & $\begin{array}{l}\text { Competência do gestor em cada uma das nove competências } \\
\text { da empresa }\end{array}$ & \multirow{2}{*}{ Escala de 1 a 4} & \multirow{2}{*}{ SCRE } \\
\hline & $\begin{array}{l}\text { Competên- } \\
\text { cia profissional } \\
\text { equipe }\end{array}$ & $\begin{array}{l}\text { Média em cada uma das nove competências para todos inte- } \\
\text { grantes das URs exceto o gestor }\end{array}$ & & \\
\hline & $\begin{array}{l}\text { Procedimentos e } \\
\text { sistemas }\end{array}$ & $\begin{array}{l}\text { Sistema de Gestão Sanepar, Sistema de remuneração, Mo- } \\
\text { delo de competências, Sistemas de qualidade (ISO } 9000 \text { e } \\
\text { 14000) }\end{array}$ & $\begin{array}{l}\text { Não foi medido, } \\
\text { pois é comum a } \\
\text { todas as URs }\end{array}$ & \\
\hline
\end{tabular}

análise fatorial. Embora o relacionamento com os fornecedores seja um recurso e, por isso, merecesse ser tratado na análise fatorial juntamente com os demais recursos da perspectiva de inovação, optou-se por dar-lhe tratamento à parte. $\mathrm{O}$ motivo se deve ao fato de ela ser uma variável externa à UR, fora de seu controle direto e, em princípio, sem associação com os demais recursos de competência. No entanto, seu efeito merece ser analisado, pois é possível supor que um mau desempenho do fornecedor à montante possa comprometer os resultados da UR à jusante.

A análise fatorial foi aplicada para as competências com o objetivo de constatar em que medida elas estariam atreladas e, se possível, reuni-las no menor número de fatores e, assim, simplificar os dados para análises posteriores. $\mathrm{O}$ resultado obtido revelou que todas as competências convergiram para um único fator, denominado competências, que explicou $63 \%$ da variância. Essa convergência para um único fator é um resultado interessante: assinalou que quando um funcionário atende uma competência, por exemplo, ele tende a atender as demais.

Quanto aos demais recursos, os resultados da análise fatorial revelaram duas variáveis: densidade de recursos e satisfação dos empregados. Os dois fatores resultantes explicaram $77 \%$ da variância. O primeiro indica a quantidade de recursos materiais por ligação, ou densidade de recursos. O segundo componente englobou satisfação do empregado e automação, com uma peculiaridade: possuem sinais invertidos. Assim, parece que quanto mais 
BRUNO HENRIQUE ROCHA FERNANDES · MARIA TEREZA LEME FLEURY · JOHN MILLS

Tabela 1 - Síntese das variáveis do modelo após a análise fatorial

\begin{tabular}{|c|c|c|c|c|c|c|}
\hline $\begin{array}{l}\text { PERSPEC- } \\
\text { TIVA }\end{array}$ & $\begin{array}{l}\text { COMPONEN- } \\
\text { TES }\end{array}$ & $\begin{array}{c}\text { VARIÁVEIS AGRUPADAS } \\
\text { MAIS RELEVANTES NA } \\
\text { ANÁLISE }\end{array}$ & $\begin{array}{l}\text { CARREGAMENTO } \\
\text { DA VARIÁVEL NO } \\
\text { FATOR }\end{array}$ & $\begin{array}{l}\text { VARIÂNCIA } \\
\text { EXPLICADA }\end{array}$ & ACEITAÇÃO & OBSERVAÇÃO \\
\hline \multirow{4}{*}{ Financeira } & \multirow{2}{*}{$\begin{array}{l}\text { Receitas e } \\
\text { despesas: }\end{array}$} & Receita operacional & 0,979 & \multirow{2}{*}{65,2} & \multirow{2}{*}{ Sim } & \multirow{2}{*}{$\begin{array}{l}\mathrm{KMO}=0,701 \\
\text { Fator escolhido }\end{array}$} \\
\hline & & Despesas UR & 0,969 & & & \\
\hline & \multirow{2}{*}{$\begin{array}{l}\text { Indicadores } \\
\text { financeiros } \\
\text { líquidos: }\end{array}$} & EBITDA & $-0,828$ & \multirow{2}{*}{22,6} & \multirow{2}{*}{ Não } & \multirow{2}{*}{$\begin{array}{l}\text { (menor variância } \\
\text { explicada) }\end{array}$} \\
\hline & & Margem Operacional & 0,848 & & & \\
\hline \multirow{2}{*}{ Clientes } & \multirow{2}{*}{$\begin{array}{l}\text { Satisfação } \\
\text { clientes: }\end{array}$} & Satisfação clientes & 0,824 & \multirow{2}{*}{67,9} & \multirow{2}{*}{ Não } & \multirow{2}{*}{$\begin{array}{l}\text { KMO = 0,5 }(<0,7 .) \\
\text { Uso da variável original } \\
\text { satisfação clientes. }\end{array}$} \\
\hline & & Reclamações & $-0,824$ & & & \\
\hline \multirow{9}{*}{$\begin{array}{l}\text { Processos } \\
\text { Internos }\end{array}$} & \multirow{2}{*}{ Metas água: } & Aumento ligações água & 0,880 & \multirow{2}{*}{60,0} & \multirow{2}{*}{ Sim } & \multirow{2}{*}{$\begin{array}{l}\text { KMO = 0,775 } \\
\text { Fator escolhido (maior } \\
\text { variância explicada) }\end{array}$} \\
\hline & & Nível atendimento água & 0,964 & & & \\
\hline & \multirow{2}{*}{ Metas esgoto: } & Aumento ligação esgoto & 0,876 & \multirow{2}{*}{24,0} & \multirow{2}{*}{ Não } & \multirow{2}{*}{$\begin{array}{l}\text { (menor variância } \\
\text { explicada) }\end{array}$} \\
\hline & & Nível atendimento esgoto & 0,819 & & & \\
\hline & \multirow{2}{*}{$\begin{array}{l}\text { Perdas no } \\
\text { sistema: }\end{array}$} & Perdas no faturamento & 0,810 & \multirow{2}{*}{48,2} & \multirow{2}{*}{ Não } & \multirow{5}{*}{$\begin{array}{l}\mathrm{KMO}=0,613(<0,7) \\
\text { Fatores excluídos }\end{array}$} \\
\hline & & Índice perdas distribuiç̧ão & 0,787 & & & \\
\hline & \multirow{3}{*}{$\begin{array}{l}\text { Reparos e } \\
\text { consertos: }\end{array}$} & Refluxos de esgoto & 0,988 & \multirow{2}{*}{21,3} & \multirow{2}{*}{ Não } & \\
\hline & & Reposição pavimento & 0,966 & & & \\
\hline & & $\begin{array}{l}\text { Interrupções } \\
\text { abastecimento: }\end{array}$ & 0,899 & 17,7 & Não & \\
\hline & & Treinamento funcionário & 0,959 & & & \\
\hline & Densidade & Recursos materiais & 0,640 & 550 & Sim & \\
\hline & recursos: & Número funcionários & 0,957 & 35,9 & SIIII & $\mathrm{KMO}=0,759$ \\
\hline & & Horas extras & 0,940 & & & Fatores escolhidos \\
\hline & Satisfação & Satisfação funcionários & 0,854 & 200 & Sim & \\
\hline & funcionário & Grau de automação & $-0,823$ & 20,9 & SIIII & \\
\hline Aprendiza- & & Relacionamento & 0,632 & & & \\
\hline do e & & Aprimoramento processo & 0,545 & & & \\
\hline to & & Orientação ao cliente & 0,686 & & & \\
\hline & & Responsabilidade & 0,672 & & & \\
\hline & $\begin{array}{l}\text { Competência } \\
\text { profissional: }\end{array}$ & Gestão do conhecimento & 0,648 & 62,8 & Sim & $\begin{array}{l}\mathrm{KMO}=0,947 \\
\text { Fator escolhido }\end{array}$ \\
\hline & & Visão do negócio & 0,595 & & & \\
\hline & & Gestão integrada & 0,693 & & & \\
\hline & & Orientação a resultados & 0,565 & & & \\
\hline & & Multifuncionalidade & 0,619 & & & \\
\hline
\end{tabular}


automatizada uma unidade, menor o grau de satisfação de seus empregados.

\section{Análise de regressão}

Para refinar o modelo e preparar as análises de regressão, duas variáveis foram adicionadas ao modelo: realização das previsões de consumo e desempenho dos fornecedores. A primeira foi incluída porque o modelo assume que previsões realizadas no planejamento irão acontecer. Se não ocorrem, o desempenho fica comprometido por motivo não relacionado a recursos ou competência. A segunda variável visou avaliar até que ponto o fornecedor afeta o resultado da UN. Um novo mapa causal foi desenhado com as novas variáveis reduzidas e variáveis adicionadas, conforme a Figura 5.

Para resumir, o modelo propõe que as variáveis da base (recursos) afetam as metas relativas ao fornecimento de água. Tais metas, se alcançadas, influenciarão a satisfação do consumidor e permitirão o alcance das metas de faturamento e despesas. Uma análise de regressão foi conduzida para testar tais relações, examinando pares de variáveis quando a associação entre uma e outra tinha significado teórico. A Tabela 2 expõe os resultados.

Os resultados mostram associações significativas entre o recurso satisfação do empregado e as três perspectivas da performance $(\mathrm{p}<0,05)$. A densidade de recursos se revelou associada com a perspectiva de processos internos e as metas financeiras, mas não com a perspectiva dos clientes. As previsões de consumo residencial revelaram associação mais forte sobre os processos internos e as metas financeiras. As competências dos empregados e o desempenho dos fornecedores não demonstraram associação com a performance da UN. Cabe ressaltar, no entanto, que o desenho desta pesquisa não permite afirmar que se trate de uma relação causal, apenas que os fenômenos estão relacionados. No modelo foi testado o efeito mediador (Baron e Kenny, 1986) exercido pela variável metas de água na relação entre as variáveis independentes e as dependentes.

\section{CONCLUSÃO}

Partindo dos pressupostos da RBV, este artigo assume o conceito de competência organizacional como um conjunto de recursos coordenados que impactam o desempenho organizacional. Entretanto, uma revisão da literatura no campo utilizando o modelo do BSC para organizar as perspectivas da performance revelou que estudos na área escolhem um tipo de recurso - por exemplo, práticas de $\mathrm{RH}$ - e examinam seu impacto sobre variáveis ligadas a uma perspectiva de performance, por exemplo, a perspectiva financeira. Poucos estudos examinam ao mesmo tempo mais de uma categoria de recursos - dentro das categorias propostas pela RBV - e sua influência sobre as várias perspectivas do desempenho simultaneamente. $\mathrm{O}$

Figura 5 - Mapa causal com variáveis reduzidas e adicionadas

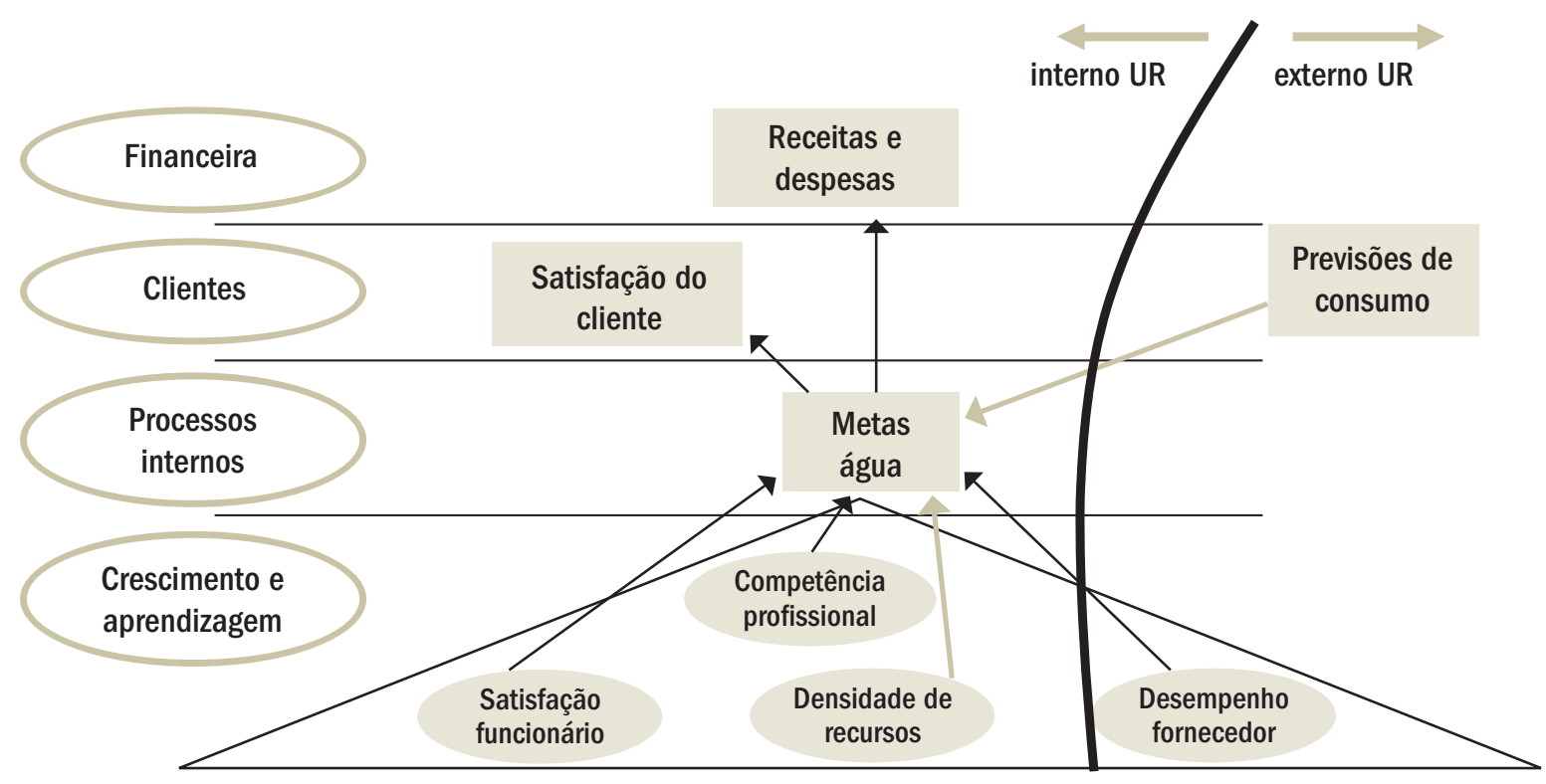


presente artigo examinou esta questão em uma companhia de saneamento, investigando recursos e indicadores de desempenho distribuídos nas quatro perspectivas do BSC e assinalados por gestores com sendo relevantes.

A companhia, constituída de UNs de mesma natureza, administradas sob os mesmos instrumentos de gestão, assegurou a comparabilidade necessária à realização do estudo. Em entrevistas com gestores da empresa, destacou-se a competência organizacional foco em resultados. Os recursos associados à concretização da competência incluíram sistemas de gestão da empresa, satisfação dos funcionários, nível de competência profissional de gestores e equipe, entre outros. Do lado do desempenho, foram enumerados indicadores nas perspectivas de processos internos, clientes e financeiras.

A fim de reduzir o número de variáveis, procedeu-se a análises fatoriais. Ao final do processo, restaram oito variáveis, que, segundo os gestores, se concatenavam dentro da seguinte lógica: os recursos satisfação dos empregados, competência profissional, densidade de recursos e desempenho dos fornecedores, coordenados sob a competência foco em resultados, garantem que a UR atinja suas metas relativas ao fornecimento de água (metas de água). Tais metas, alcançadas, influenciam a satisfação de clientes e permitem atingir as metas de receitas e despesas, desde que não ocorram intercorrências externas (variável realização das previsões de consumo).

Em geral, as variáveis estão correlacionadas. A competência foco em resultado parece resultar da coordena- ção dos recursos satisfação dos empregados e densidade de recursos. Outros detalhes que apareceram na análise foram: o grau de competência profissional, segundo a forma medida pela empresa, não apresentou associação com variáveis de desempenho; os fatores ambientais relacionados ao consumo residencial apareceram como o mais forte determinante da performance; a satisfação dos empregados demonstrou associação com metas de processos internos, com metas financeiras e com a satisfação dos consumidores.

O primeiro resultado é curioso. Sugere que o nível de competência profissional das pessoas não é muito relevante em URs. Possíveis explicações para tal resultado são: o desenvolvimento de competências apresenta resultados a longo prazo, e a pesquisa coletou e analisou dados no horizonte de um ano, tempo talvez insuficiente para revelar os frutos de tal desenvolvimento; na pesquisa, as UNs testadas eram de nível bastante operacional, em que recursos como normas e procedimentos pareciam ser o principal mecanismo de coordenação. Nessas circunstâncias, seguir os procedimentos pode ser mais importante que o nível de desenvolvimento das pessoas.

A pesquisa apresentou limitações. Uma primeira é que, ao agrupar variáveis sob forma de fatores, perderam-se informações e, portanto, sensibilidade nos resultados, ou seja, não foi possível depurar com precisão o impacto de cada recurso. Uma segunda é que o estudo teve foco horizontal comparativo, e talvez por isso não tenha conseguido apreender o impacto do desenvolvimento de competências

Tabela 2 - Análise de regressão: como os recursos se relacionam ao desempenho

\begin{tabular}{|c|c|c|c|c|}
\hline \multicolumn{2}{|l|}{ V. INDEPENDENTES } & METAS DE ÁGUA & $\begin{array}{l}\text { SATISFAÇÃO DOS } \\
\text { CLIENTES }\end{array}$ & RECEITAS E DESPESAS \\
\hline \multirow{2}{*}{$\begin{array}{l}\text { Satisfação dos } \\
\text { empregados }\end{array}$} & $R_{\text {ajustado }}^{2}$ & 0,405 & 0,227 & 0,090 \\
\hline & Valor-p & 0,000 & 0,001 & 0,037 \\
\hline \multirow{2}{*}{$\begin{array}{l}\text { Competência } \\
\text { Profissional }\end{array}$} & $R_{\text {ajustado }}^{2}$ & $-0,017$ & $-0,014$ & $-0,027$ \\
\hline & Valor-p & 0,538 & 0,492 & 0,907 \\
\hline \multirow{2}{*}{$\begin{array}{l}\text { Densidade de } \\
\text { Recursos }\end{array}$} & $R_{\text {ajustado }}^{2}$ & 0,110 & $-0,015$ & 0,104 \\
\hline & Valor-p & 0,023 & 0,510 & 0,027 \\
\hline \multirow{2}{*}{$\begin{array}{l}\text { Desempenho } \\
\text { fornecedores }\end{array}$} & $R_{\text {ajustado }}^{2}$ & 0,021 & $-0,026$ & $-0,013$ \\
\hline & Valor-p & 0,189 & 0,822 & 0,472 \\
\hline \multirow{2}{*}{ Previsões de consumo } & $R_{\text {ajustado }}^{2}$ & 0,620 & 0,059 & 0,405 \\
\hline & Valor-p & 0,000 & 0,077 & 0,000 \\
\hline \multirow{2}{*}{$\begin{array}{l}\text { Metas de } \\
\text { Água }\end{array}$} & $R_{\text {ajustado }}^{2}$ & & 0,232 & 0,377 \\
\hline & Valor-p & & 0,001 & 0,000 \\
\hline
\end{tabular}


profissionais no desempenho organizacional. Uma terceira limitação, inerente à pesquisa social aplicada, decorre do empobrecimento da realidade no momento de sua operacionalização sob forma de variáveis de pesquisa. Uma quarta limitação é quanto ao tamanho reduzido da amostra para utilizar técnicas de modelagem de equações estruturais, mais apropriadas para aferir relações causais.

Para pesquisas futuras neste campo, sugere-se o enfoque de empresas intensivas em conhecimento, nas quais é possível que o grau de competência dos indivíduos surja como fator essencial, bem como a realização de estudos empíricos longitudinais para avaliar o impacto de competências pessoais específicas do gestor e da equipe no desempenho.

\section{NOTAS}

1 "Existe considerável sopa terminológica, com vários teóricos da RBV usando conceitos como 'recursos', 'competências', 'capacidades', 'ativos', etc. para o que é, muitas vezes, a mesma coisa” (Foss, 1997, p. 346). Inclusive, Foss argumenta que essa confusão tem sido uma limitação ao desenvolvimento da RBV.

${ }^{2}$ Por mais que a competência se manifeste nos indicadores de desempenho, essa relação não é necessária, uma vez que o desempenho depende de fatores externos à organização. Assim, pode acontecer que, num ano, uma organização reconhecida por sua competência de inovação não realize inovação substantiva, e nem por isso deixaria de ter a competência. Porém, tais fatos serão esporádicos, e o normal é que, em um período de tempo longo, os indicadores acompanhem a competência.

${ }^{3}$ Ainda que a fundamentação teórica argumente que a competência - enquanto recursos coordenados - influencia o desempenho, tanto a revisão de pesquisas quanto a parte empírica deste estudo enfatizam como recursos individuais afetam o desempenho, independentemente de estarem articulados a outros recursos sob forma de competências. O construto "competências" será utilizado na metodologia e na interpretação dos resultados.

\section{REFERÊNCIAS}

ARTHUR, J. Effects of human resource systems on manufacturing performance and turnover. Academy of Management Journal, v .37, n. 3, p. 670-687, 1994.

BAE, J.; LAWLER, J. Organizational and HRM strategies in Korea: impact on firm performance in an emerging economy. Academy of Management Journal, v. 43, n. 3, p. 502-517, 2000.

BARBER, L. et al. From people to profits. Brighton: The Institute for Employment Studies. Report 355, 1999.

BARNEY, J. Firm resources and sustained competitive advantage. Journal of Management, v. 17, n. 1, p. 99-120, 1991.
BARNEY, J. Gaining and Sustaining Competitive Advantage. New York: Addison-Wesley, 1996.

BARON, R., KENNY, D. The moderator-mediator distinction in social psychological research: conceptual, strategic, and statistical considerations. Journal of Personality and Social Psychology, v. 51, n. 6, p. 11731182, 1986.

BATT, R. Managing customer services: human resource practices, quit rates and sales growth. Academy of Management Journal, v. 45, n. 3, p.587597,2002

BECKER, B. et al. The HR Scorecard: Linking People, Strategy and Performance. Boston: Harvard Business School Press, 2001.

BECKER, B.; GERHART, B. The impact of human resources management on organizational performance: progress and prospects. Academy of Management Journal, v. 39. n. 4, p. 779-801, 1996.

CAMERON, K. Effectiveness as paradox: consensus and conflict in conceptions of organizational effectiveness. Management Science, v. 32, n. 5 , p. $539-553,1986$.

DELANEY, J.; HUSSELID, M. The impact of human resources management practices on perceptions of organizational performance. Academy of Management Journal. v. 39, n. 4, p. 949-969, 1996.

FARIAS, G.; VARMA. A. High performance work systems: what we know and what we need to know. Human Resource Planning, v. 21, n. 2, p. $50-$ 55,1998

FOSS, N. J. Resources, Firms and Strategies: A Reader in the Resource-Based Perspective. Oxford: Oxford University Press, 1997.

FULMER, I. S.; GERHART, B.; SCOTT, K. S. Are the 100 best better? An empirical investigation of the relationship between being a "great place to work" and firm performance. Personnel Psychology, v. 56, n. 4, p. 985993, 2003.

GALES, H. et al. Skills, flexible manufacturing technology, and work organization. Industrial Relations, v. 41, n. 1, p. 48-79, 2002.

GUTHRIE, J. High-involvement work practices, turnover, and productivity: evidence form New Zealand. Academy of Management Journal, v. 44, n.1, p. 180-190, 2001.

HAIR, J. et al. Multivariate Data Analysis. Englewood Cliffs, NJ: PrenticeHall, 1998.

HAMEL, G. The concept of core competence. In: HAMEL, G.; HEENE, A. (Eds.). Competence-Based Competition. Chichester, UK: John Wiley and Sons, 1994. p. 11-34.

HENRI, J. Performance measurement and organizational effectiveness: bridging the gap. Managerial Finance, v. 30, n. 6, p. 93-123, 2004.

HESKETT, J.; SASSER JR., W. E.; SCHLESINGER, L. A. The Service Profit Chain: How Leading Companies Link Profit And Growth to Loyalty, Satisfaction and Value. NY: Free Press, 1997.

HITT, M.; BIERMAN, L; SHIMIZU, K.; KOCHHAR, R. Direct and moderating effects of human capital on strategy and performance in professional service firms: a resource-based perspective. Academy of Management Journal, v. 44, n. 1, p. 13-28, 2001. 
HOFFMAN, K; INGRAM, T. Service provider job satisfaction and customer-oriented performance. Journal of Services Marketing, v. 6, n. 2, p. 68-78, 1992

HUSSELID, M. A.; JACKSON, S. E.; SCHULER, R. S. Technical and strategic human resource management effectiveness as determinants of firm performance. Academy of Management Journal, v. 40, n. 1, p. 171-188, 1997.

HUSSELID, M. Impact of human resource management on turnover, productivity and corporate financial performance. Academy of Management Journal, v. 38, n. 3, p. 635-672, 1995.

KAPLAN, R.; NORTON, D. Mapas estratégicos: convertendo ativos intangíveis em resultados tangíveis. Tradução Afonso Serra. Rio Janeiro: Campus, 2004.

KAPLAN, R.; NORTON, D. Organização orientada para a estratégia: como as empresas que adotam o balanced scorecard prosperam no novo ambiente de negócios. Tradução Afonso Serra. Rio Janeiro: Campus, 2001.

KAPLAN, R.; NORTON, D. The balanced scorecard - measures that drive performance. Harvard Business Review, v. 70, n. 1, p. 71-79, 1992.

LEONARD, D. Wellspring of Knowledge: Building and Sustaining the Sources of Innovation. Boston: Harvard Business School Press, 1995.

MILLS, J.; PLATTS, K.; BOURNE, M.; RICHARDS, H. Competing Through Competences. Cambridge: University Press, 2002.
MUELLER, F. Human resource as strategic assets: an evolutionary resource-based theory. Journal of Management Studies, v. 33, n. 6, p. 757-785, 1996.

NEELY, A.; NAJJAR, M. Linking financial performance to employee and customer satisfaction. In NEELY, A. (Eds.). Business Performance Measurement: Theory and Practice. Cambridge: Cambridge University Press, 2003. p. 295-303.

PENROSE, E. The Theory of Growth of the Firm. London: Basil Blackwell, 1959.

PRAHALAD, C.; HAMEL, G. The core competences of the corporation. Harvard Business Review, v. 68, n. 3, p. 79-91, 1990.

PUGH, D. Service with a smile: emotional contagion in the service encounter. Academy of Management Journal, v. 44, n. 5, p. 1018-1027, 2001.

RUCCI, A.; KIRN, S.; QUINN, R. The employee-customer-profit chain at Sears. Harvard Business Review, v. 76, n. 1, p. 83-97, 1998.

SANARE. Revista Técnica da Sanepar, v. 18, n. 18, 2002.

SCHAY, B. et al. Using standardized outcome measures in the federal government. Human Resource Management, v. 41, n. 3, p. 355-368, 2002.

SUSSKIND, A. et al. Customer service providers' attitudes relating to customer service and customer satisfaction in the customer-server exchange. Journal of Applied Psychology, v. 88, n. 1, p. 179-187, 2003.

VARMA, A. et al. High performance work systems: exciting discovery or passing fad? Human Resource Planning, v. 22, n. 1, p .26- 37, 1999.

Artigo recebido em 27.09.2004. Aprovado em 18.04.2006.

\section{Bruno Henrique Rocha Fernandes}

Professor do mestrado em Administração do Centro Universitário Positivo. Doutor em Administração pela USP.

Interesses de pesquisa nas áreas de gestão de competências, gestão estratégica de pessoas, avaliação de desempenho organizacional e gestão internacional.

E-mail: bruno@unicenp.edu.br

Endereço: R. Nunes Machado, 2431, Parolin, Curitiba - PR, 80220-070.

\section{Maria Tereza Leme Fleury}

Professora titular da FEA-USP. Doutora em Sociologia pela FFLCH-USP.

Interesses de pesquisa nas áreas de gestão de competências, cultura organizacional e gestão internacional.

Email: mtfleury@usp.br

End: Av. Prof Luciano Gualberto, 908, Cidade Universitária, São Paulo-SP, 05508-900.

\section{John Mills}

Senior Research Fellow. Centre for Strategy \& Performance, Institute for Manufacturing - University of Cambridge.

Interesse de pesquisa nas áreas de competências organizacionais, avaliação de desempenho organizacional e administração da produção.

E-mail: jfm@eng.cam.ac.uk

Endereço: Institute for Manufacturing, Department of Engineering, University of Cambridge, Mill Lane - UK, CB2 1RX. 